\title{
Hereditary motor and sensory neuropathy type 5
}

INSERM

\section{Source}

INSERM. (1999). Orphanet: an online rare disease and orphan drug data base. Hereditary motor and sensory neuropathy type 5. ORPHA:64751

Hereditary motor and sensory neuropathy type 5 is a rare axonal hereditary motor and sensory neuropathy characterized by slowly progressive distal muscle weakness and atrophy with or without sensory loss resulting in difficulty in walking, foot drop and pes cavus, that may be associated with pyramidal signs (extensor plantar responses, mild increase in tone, brisk tendon reflexes), muscle cramps, pain and spasticity. 